\title{
Cyclic AMP increases the survival of ganglion cells in mixed retinal cell cultures in the absence of exogenous neurotrophic molecules, an effect that involves cholinergic activity
}

R.C.C. Santos and E.G. Araujo

\author{
Programa de Neuroimunologia, Departamento de Neurobiologia, \\ Instituto de Biologia, Universidade Federal Fluminense, Niterói, RJ, Brasil
}

Correspondence
E.G. Araujo
Departamento de Neurobiologia
Instituto de Biologia, UFF
Caixa Postal 100.180
$24001-970$ Niterói, RJ
Brasil
Fax: + 55-21-2719-5934
E-mail: adrianno@ openlink.com.br
Research supported by FAPERJ,
CAPES and PRO NEX-M CT.
R.C.C. Santos is the recipient of
a CAPES fellowship.
$\ldots \ldots \ldots . . . \ldots . . . . . . . . .$.

Received January 26, 2001 Accepted September 3, 2001

\section{Abstract}

Natural cell death is a well-known degenerative phenomenon occurring during development of the nervous system. The role of trophic molecules produced by target and afferent cells as well as by glial cells has been extensively demonstrated. Literature data demonstrate that cAMP can modulate the survival of neuronal cells. Cultures of mixed retinal cells were treated with forskolin (an activator of the enzyme adenylyl cyclase) for $48 \mathrm{~h}$. The results show that $50 \mu \mathrm{M}$ forskolin induced a two-fold increase in the survival of retinal ganglion cells (RGCs) in the absence of exogenous trophic factors. This effect was dose dependent and abolished by $1 \mu \mathrm{M}$ H89 (an inhibitor of protein kinase A), $1.25 \mu \mathrm{M}$ chelerythrine chloride (an inhibitor of protein kinase C), $50 \mu \mathrm{M}$ PD 98059 (an inhibitor of MEK), $25 \mu \mathrm{M}$ Ly 294002 (an inhibitor of phosphatidylinositol-3 kinase), $30 \mathrm{nM}$ brefeldin A (an inhibitor of polypeptide release), and $10 \mu \mathrm{M}$ genistein or $1 \mathrm{ng} / \mathrm{ml}$ herbimycin (inhibitors of tyrosine kinase enzymes). The inhibition of muscarinic receptors by $10 \mu \mathrm{M}$ atropine or $1 \mu \mathrm{M}$ telenzepine also blocked the effect of forskolin. When we used $25 \mu \mathrm{M}$ BAPTA, an intracellular calcium chelator, as well as $20 \mu \mathrm{M}$ 5-fluoro-2'-deoxyuridine, an inhibitor of cell proliferation, we also abolished the effect. Our results indicate that cAMP plays an important role controlling the survival of RGCs. This effect is directly dependent on M1 receptor activation indicating that cholinergic activity mediates the increase in RGC survival. We propose a model which involves cholinergic amacrine cells and glial cells in the increase of RGC survival elicited by forskolin treatment.

\section{Introduction}

Apoptosis, or naturally occurring cell death, is an active process of cellular selfdestruction with distinctive morphological and biochemical features. During apoptosis

\section{Key words}

- Ganglion cell survival

- cAMP

- Amacrine cholinergic cells

- M1 receptor activity

- Glial cells 
regressive event is essential for normal development, the molecular mechanisms that carry it out must be properly regulated; when this regulation is disturbed, diseases can appear (2).

During the development of the nervous system, naturally occurring cell death is an important event accompanying synaptogenesis (3). It has been assumed that an excessive number of neuronal cells is generated in order to promote appropriate neuronal connections to fit neuronal projection to the size and function of target cells $(3,4)$. Target cells produce and release trophic molecules known as neurotrophins (NT) which play a crucial role in the differentiation, survival and plasticity of developing neurons $(5,6)$. Several polypeptides including nerve growth factor (NGF), brain-derived neurotrophic factor (BDNF), NT-3, NT-4/5 and NT-6 belong to a neurotrophic family (7-9). All of these molecules bind to the low affinity receptor p75 (10). However, high affinity receptors (Trk) show a relative selectivity since NGF binds to TrkA, BDNF and NT-4/5 bind to TrkB, and NT-3 binds to TrkC $(11,12)$.

Afferent cells also play an important role controlling natural cell death in the nervous system. Some of the mechanisms involved in afferent control of cell death are not clearly understood but the electrical activity as well as the release of trophic factors by either afferent or glial cells are evident (5).

Intracellular calcium concentration plays an important role in the regulation of apoptosis. Several lines of evidence show that an increase of cytoplasmic calcium can either block or trigger apoptosis, depending on the cell type studied (13).

Adenosine 3',5'-cyclic monophosphate (cAMP) is a key second messenger in signaling pathways governing many cellular processes. Many signals that regulate the growth, development and metabolism of cells use cAMP as a second messenger. Experimental data show that the second messenger cAMP is also involved in the control of neuronal cell death (14). This second messenger activates a protein kinase A (PKA) which is a tetrameric holoenzyme consisting of a dimeric regulatory subunit and two monomeric catalytic subunits (15). The action of cAMP is interrupted by one or more cyclic nucleotide phosphodiesterases (16). Literature data have shown that cAMP can increase the survival of sympathetic, spinal motor and dopaminergic neurons in vitro in the absence of neurotrophic factors (17). It has also been suggested that cAMP could also modulate the differentiation of brainstem catecholaminergic neurons (18).

The aim of the present investigation was to determine the effect of cAMP on ganglion cell survival kept in mixed retinal cell cultures in the absence of exogenous neurotrophic molecules. We used $50 \mu \mathrm{M}$ forskolin to stimulate an increase in cAMP levels in the cultures. Our results demonstrate that the effect of forskolin is dose dependent and involves an increase in cytoplasmic calcium levels, activation of protein kinases, release of polypeptides, and cellular proliferation. An important finding is that cholinergic activity mediates the effect of forskolin, indicating an important role for this neurotransmitter in the control of retinal ganglion cell survival.

\section{Material and Methods}

Within the first $24 \mathrm{~h}$ after birth, Lister Hooded rats were anesthetized by hypothermia. One microliter of a solution of $30 \%$ horseradish peroxidase (HRP) in $2 \%$ dimethyl sulfoxide was injected into each superior colliculus. The animals survived for $\sim 16 \mathrm{~h}$ before the procedures used for cell culture.

Neonatal rats were killed by decapitation and the eyes were rapidly removed and immersed in a calcium- and magnesium-free (CMF) salt solution. Retinas were gently isolated and incubated at $37^{\circ} \mathrm{C}$ for $20 \mathrm{~min}$ in CMF containing $0.2 \%(\mathrm{w} / \mathrm{v})$ trypsin (Wor- 
thington, Freehold, NJ, USA). The tissue was then resuspended in complete culture medium and triturated by passage through a Pasteur pipette. After complete tissue dissociation, $1 \mathrm{ml}$ of the cell suspension was added to glass coverslips previously coated with $50 \mu \mathrm{g} / \mathrm{ml}$ poly-L-ornithine and placed on 35-mm Petri dishes. We used 199 medium supplemented with $2 \mathrm{mM}$ glutamine, 100 $\mu \mathrm{g} / \mathrm{ml}$ streptomycin, $100 \mathrm{U} / \mathrm{ml}$ penicillin and $5 \%$ fetal calf serum. After cell plating, cultures were usually incubated for $4 \mathrm{~h}$ to allow the cells to attach to the coverslips. Then, culture medium alone or culture medium containing the drugs to be tested was added to each Petri dish. Average plating density was 650,000 cells per Petri dish. The cultures were maintained in a humidified atmosphere of $5 \% \mathrm{CO}_{2}$ and $95 \%$ air at $37^{\circ} \mathrm{C}$.

The presence of the enzyme peroxidase in the cytoplasm of retinal ganglion cells was demonstrated by the protocol of Mesulam (19). Briefly, the monolayers were fixed after 2 days in culture with a mixture of $1 \%$ paraformaldehyde and $2 \%$ glutaraldehyde in $0.1 \mathrm{M}$ sodium phosphate buffer for $5 \mathrm{~min}$, washed in phosphate buffer, and reacted with tetramethylbenzidine.

Retinal ganglion cells were counted using a Zeiss microscope at a magnification of 400X under a bright field. As an internal control for the percentage of ganglion cells labeled with HRP in distinct experiments, the number of labeled cells after $4 \mathrm{~h}$ in culture was taken as $100 \%$. All data are reported as mean \pm standard error of the mean of experiments performed at least in duplicate and each experiment was repeated at least three times. Statistical analysis was done using analysis of variance (ANOVA) followed by the Newman-Keuls test.

\section{Results}

We first analyzed the effect of forskolin on the survival of retinal ganglion cells after $48 \mathrm{~h}$ in culture. Figure 1 shows that treatment with forskolin increased the survival of ganglion cells in a dose-dependent way. After $48 \mathrm{~h}$ the number of retinal ganglion cells in control cultures was reduced by approximately $50 \%$. However, 10, 25 and $50 \mu \mathrm{M}$ forskolin induced an increase in ganglion cell survival. The strongest effect was obtained with $50 \mu \mathrm{M}$ forskolin (approximately all cells initially plated were alive after $48 \mathrm{~h}$ ). Based on these results, we used $50 \mu \mathrm{M}$ forskolin in all subsequent experiments.

To investigate if the forskolin effect was dependent on culture density we used two different plating densities (130 and 65 cells/ $\mathrm{mm}^{2}$ ). The results presented in Table 1 show that forskolin enhanced ganglion cell sur-

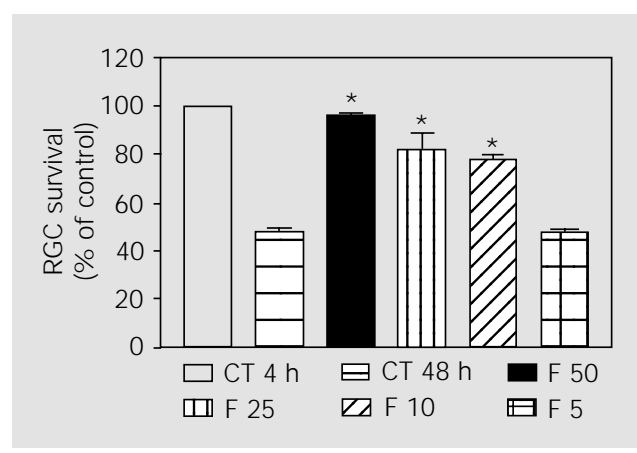

Table 1. The effect of $50 \mu \mathrm{M}$ forskolin on ganglion cell survival at different plating densities.

\begin{tabular}{lcc}
\hline \multirow{2}{*}{ Treatment } & \multicolumn{2}{c}{ RGC survival (\% of control) } \\
\cline { 2 - 3 } & 65 cells $/ \mathrm{mm}^{2}$ & 130 cells $/ \mathrm{mm}^{2}$ \\
\hline 48-h Control & $57.25 \pm 1.05$ & $48.62 \pm 1.07$ \\
Forskolin & $106.30 \pm 8.89 *$ & $87.18 \pm 6.92 *$
\end{tabular}

We used two different plating densities (130 cells/ $\mathrm{mm}^{2}$ and 65 cells $/ \mathrm{mm}^{2}$ ). Forskolin enhanced the survival of retinal ganglion cells (RGCs) at both densities studied. The number of RGCs counted in 4 -h cultures was 25,160 cells ( 130 cells $/ \mathrm{mm}^{2}$ ) and 12,670 cells ( 65 cells $/ \mathrm{mm}^{2}$ ). Data are reported as the percentage of RGC survival compared with 4-h control cultures $(100 \%)$ and represent the mean \pm SEM of three different experiments, each performed with at least three different Petri dishes $(\mathrm{N}=3-4)$. $* \mathrm{P}<0.001$ compared to the $48-\mathrm{h}$ control (Newman-Keuls test).
Figure 1. Dose-dependent effect of forskolin on retinal ganglion cell (RGC) survival after $48 \mathrm{~h}$ in culture. Cultures were treated with forskolin $(5,10,25$ and 50 $\mu \mathrm{M}) . \mathrm{CT}=$ control, $\mathrm{F}=$ forskolin. The number of RGCs counted in 4-h cultures was 21,140 cells. Data are reported as the percentage of RGC survival compared with 4-h control cultures $(100 \%)$ and represent the mean \pm SEM of two different experiments, each performed with at least three different Petri dishes $(\mathrm{N}=3-4) . * \mathrm{P}<0.001$ compared to the 48-h control (NewmanKeuls test). 
vival at both densities studied. For this reason we used the density of 65 cells $/ \mathrm{mm}^{2}$ in all subsequent experiments.

To test if the effect of forskolin was dependent on chronic treatment we exposed the cultures to a 12- or 24-h pulse of this drug. Analyzing the results obtained we concluded that the increase in ganglion cell survival was observed only when forskolin was present during the whole period of culture (data not shown).

Literature data suggest that forskolin itself may induce a neurotrophic effect. To

Table 2. CAMP and retinal ganglion cell survival.

\begin{tabular}{lc} 
Treatment & RGC survival (\% of control) \\
\hline 48-h Control & $57.84 \pm 0.46$ \\
Dibutyryl cAMP & $96.26 \pm 2.05^{*}$ \\
Cholera toxin & $83.51 \pm 4.88^{*}$ \\
IBMX $(200 \mu \mathrm{M})$ & $82.52 \pm 2.81^{*}$ \\
IBMX $(400 \mu \mathrm{M})$ & $96.16 \pm 2.23^{*}$ \\
\hline
\end{tabular}

We used $1 \mathrm{mM}$ dibutyryl cAMP, $100 \mathrm{ng} / \mathrm{ml}$ cholera toxin and 200 or $400 \mu \mathrm{M}$ IBMX. All of these drugs induced the same effect as elicited by 50 $\mu \mathrm{M}$ forskolin on retinal ganglion cell (RGC) survival after $48 \mathrm{~h}$ in vitro. The number of RGCs counted in 4-h cultures was at least 18,260 cells. Data are reported as the percentage of RGC survival compared with $4-\mathrm{h}$ control cultures $(100 \%)$ and represent the mean \pm SEM of three different experiments, each performed with at least two different Petri dishes ( $\mathrm{N}=3-4$ ). $* \mathrm{P}<0001 \mathrm{com}$ pared to the 48-h control (Newman-Keuls test).

Figure 2. The effect of $50 \mu \mathrm{M}$ forskolin was inhibited by $25 \mu \mathrm{M}$ BAPTA-AM. Cells were maintained in vitro for $48 \mathrm{~h}$. Nifedipine $(7.5 \mu \mathrm{M})$ and $30 \mu \mathrm{M}$ dantrolene did not block the effect of forskolin. CT = control, $F=$ forskolin, Nif = nifedipine (an inhibitor of voltage dependent L-type calcium channels), Dan = dantrolene (an inhibitor of internal calcium release), BAPTA-AM (an intracellular calcium chelator). The number of retinal ganglion cells

(RGCs) counted in 4-h cultures was 13,350 cells. Data are reported as the percentage of RGC survival compared with 4-h control cultures (100\%) and represent the mean \pm SEM of three different experiments, each performed with at least three different Petri dishes $(\mathrm{N}=$ 3-6). $* \mathrm{P}<0.001$ compared to the 48-h control (Newman-Keuls test). test this hypothesis we evaluated the effect of different drugs that increase intracellular cAMP levels (Table 2). Initially we began testing a membrane permeable analog of cAMP, $1 \mathrm{mM}$ dibutyryl cAMP. The results demonstrated that this drug mimics the increase in ganglion cell survival obtained with forskolin treatment after $48 \mathrm{~h}$ in culture. To confirm this result we tested a drug that activates $\mathrm{G}$ proteins and indirectly activates adenylyl cyclase, i.e., $100 \mathrm{ng} / \mathrm{ml}$ cholera toxin. Again we obtained an increase in ganglion cell survival after this treatment. To determine if endogenous cAMP would be sufficient to increase the survival of ganglion cells in culture we used an inhibitor of phosphodiesterase, 200 or $400 \mu \mathrm{M}$ IBMX. We observed that an increase in survival was obtained following phosphodiesterase inhibition.

The next step was to determine if the effect of forskolin was mediated by an increase in cytoplasmic calcium levels. Figure 2 demonstrates that when cells were treated with forskolin in the presence of $7.5 \mu \mathrm{M}$ nifedipine (an inhibitor of voltage-dependent L-type calcium channels) or $30 \mu \mathrm{M}$ dantrolene (an inhibitor of internal calcium release), there were no changes in the effect of forskolin. On the other hand, when we used an intracellular calcium chelator $(25 \mu \mathrm{M}$ BAPTA-AM) we abolished the effect on retinal ganglion cell survival.

One major cellular effect of the cAMP cascade activation is the transcriptional stimulation after phosphorylation of nuclear factors by the cAMP-dependent kinase, PKA. To investigate the involvement of this enzyme in the effect of forskolin we used an inhibitor of PKA, $25 \mu \mathrm{M}$ H89. Figure 3 shows that PKA inhibition abolished the effect on ganglion cell survival. To test the role of other protein kinases on the effect of forskolin we used an inhibitor of protein kinase $\mathrm{C}$ (PKC), $1.25 \mu \mathrm{M}$ chelerythrine chloride. Figure 3 shows that this drug partially abolished the effect of forskolin. Since PKC 
was involved in this effect we decided to investigate if the activation of mitogen-activated protein kinase (MAPK) was mediating the effect studied. We used an inhibitor of MAPK enzyme (MEK), $25 \mu \mathrm{M}$ PD 98059, and observed that this drug completely abolished the increase in ganglion cell survival (Figure 3).

To determine if tyrosine kinase enzymes are involved in the effect of forskolin we used $10 \mu \mathrm{M}$ genistein and $1 \mathrm{ng} / \mathrm{ml}$ herbimycin (both inhibitors of these enzymes). Our results demonstrate that in the presence of these drugs the effect of forskolin was totally abolished (Figure 4). Since the activation of the tyrosine kinase pathway is involved in the effect of forskolin, we tested an inhibitor of the phosphatidylinositol (PI)-3 kinase enzyme, $25 \mu \mathrm{M}$ Ly 294002. This inhibitor completely inhibited the effect of forskolin on ganglion cell survival (Figure 4). Based on these results, we tested an inhibitor of polypeptide release, $30 \mathrm{nM}$ brefeldin A, which effectively blocked the effect of forskolin on ganglion cell survival (Figure 5).

Morphological analysis of retinal cells in culture showed that glial cells keep their proliferative capacity throughout in vitro culture. To determine if the effect of forskolin was mediated by an increase in glial cell population we tested it in the presence of an inhibitor of cell division, $25 \mu \mathrm{M}$ fluorodeoxyuridine. Figure 6 shows that treatment with this antimitotic drug abolished the effect of forskolin. This result indicates that ganglion cell survival induced by forskolin is mediated by an increase in the number of glial cells.

In order to verify the cholinergic activity of a subset of amacrine cells in our cultures we tested an antagonist of muscarinic receptors, $10 \mathrm{mM}$ atropine, and obtained a complete inhibition of the forskolin effect (Figure 7). To investigate which subtype of muscarinic receptors could be involved in the effect of forskolin we tested M1 and M3 antagonists, $1 \mu \mathrm{M}$ telenzepine and $200 \mu \mathrm{M}$
DAMP, respectively. Figure 7 shows that only telenzepine was able to abolish the effect of forskolin on cultures. This result suggests that the activation of M1 receptors is involved in the survival of ganglion cells in vitro.

Figure 3. The effect of $50 \mu \mathrm{M}$ forskolin was abolished by inhibition of protein kinase activity. Cells were maintained in vitro for 48 h. $C T=$ control, $F=$ forskolin, H89 (an inhibitor of PKA), PD = PD 98059 (an inhibitor of MEK), $\mathrm{CC}=$ chelerythrine chloride (an inhibitor of PKC). The number of retinal ganglion cells (RGCS) counted in 4-h cultures was 10,000 cells. Data are reported as the percentage of RGC survival compared with 4-h control cultures $(100 \%)$ and represent the mean \pm SEM of two different experiments, each performed with at least three different Petri dishes $(\mathrm{N}=3-6)$. *P $<0.001$ compared to the 48-h control (Newman-Keuls test).

Figure 4. The effect of $50 \mu \mathrm{M}$ forskolin was blocked by inhibition of tyrosine kinase activity. Cells were maintained in vitro for 48 h. CT = control, $\mathrm{F}=$ forskolin, $\mathrm{G}=$ genistein and $\mathrm{Hr}=$ herbimycin (inhibitors of tyrosine kinase enzymes), Ly = Ly 294002 (an inhibitor of phosphatidylinositol-3 kinase). The number of retinal ganglion cells (RGCs) counted in 4-h cultures was 27,050 cells. Data are reported as the percentage of RGC survival compared with $4-\mathrm{h}$ control cultures $(100 \%)$ and represent the mean \pm SEM of three different experiments, each performed with at least three different Petri dishes ( $N=3-6)$. *P $<0.001$ compared to the 48-h control (Newman-Keuls test).

Figure 5. The effect of $50 \mu \mathrm{M}$ forskolin was abolished by inhibition of polypeptide release. Cells were maintained in vitro for $48 \mathrm{~h}$. CT = control, $\mathrm{F}=$ forskolin, BFA $=30 \mathrm{nM}$ brefeldin A (an inhibitor of polypeptide release). The number of retinal ganglion cells (RGCs) counted in 4-h cultures was 10,650 cells. Data are reported as the percentage of RGC survival compared with 4-h control cultures (100\%) and represent the mean \pm SEM

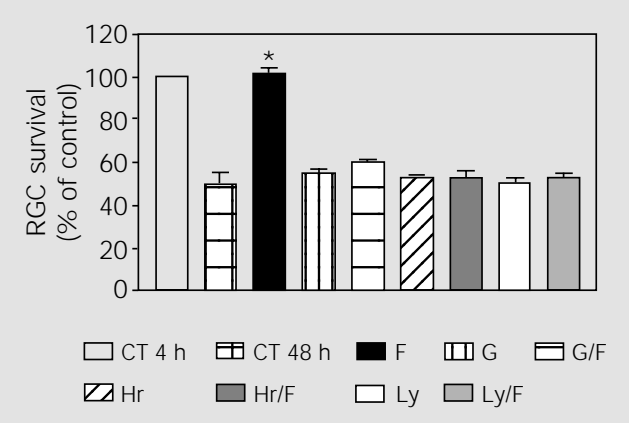

of two different experiments, each performed with at least three different Petri dishes ( $N=$ 3-6). *P<0.001 compared to the 48-h control (Newman-Keuls test). 


\section{Discussion}

The results presented in this study show that treatment of mixed retinal cell cultures with $50 \mu \mathrm{M}$ forskolin induced a two-fold increase in ganglion cell survival after $48 \mathrm{~h}$ in vitro. To investigate if these results are directly dependent on cAMP enhancement we used other drugs that increase the cytoplasmic cAMP concentration. The results presented here show that all drugs tested elicited an increase in ganglion cell survival, suggesting that this effect was mediated by cAMP. These data definitely demonstrate that cAMP signaling is really involved in the control of ganglion cell survival in mixed retinal cell cultures.

In the present study we did not analyze the effect of forskolin on the other cell types

Figure 6. The effect of $50 \mu \mathrm{M}$ forskolin was blocked by $20 \mu \mathrm{M}$ FDUR. Cells were maintained in vitro for $48 \mathrm{~h}$. $\mathrm{CT}=$ control, $\mathrm{F}=$ forskolin, FDUR = 5-fluoro-2'-deoxyuridine (inhibitor of cell proliferation). The number of retinal ganglion cells (RGCs) counted in 4-h cultures was 18,000 cells. Data are reported as the percentage of RGC survival compared with 4-h control cultures (100\%) and represent the mean \pm SEM of two different experiments, each performed with at least three different Petri dishes $(\mathrm{N}=3-6)$. $* \mathrm{P}<0.001$ compared to the 48-h control (Newman-Keuls test).

Figure 7. The effect of $50 \mu \mathrm{M}$ forskolin was inhibited by the blockade of M1 muscarinic receptors. Cells were maintained in vitro for $48 \mathrm{~h}$. $\mathrm{CT}=$ control, $\mathrm{F}=$ forskolin, $\mathrm{A}=10 \mu \mathrm{M}$ atropine (a muscarinic antagonist), $\mathrm{T}=1 \mu \mathrm{M}$ telezenpine (an $\mathrm{M} 1$ antagonist), DAMP $=200 \mu \mathrm{M}$ DAMP (an M3 antagonist). The number of retinal ganglion cells (RGCs) counted in 4-h cultures was 27,000 cells. Data are reported as the percentage of RGC survival compared with 4-h control cultures $(100 \%)$ and represent the mean \pm SEM of three different experiments, each performed with at least three different Petri dishes ( $\mathrm{N}=3-6)$. $* \mathrm{P}<0.001$ compared to the 48-h control (Newman-Keuls test). present in our cultures. Further studies will be performed in order to investigate if the effect of forskolin on survival is restricted to the ganglion cell population. However, we have observed that Müller cells proliferate during the time in culture showing a background covering on plating dishes, forming a glial "carpet" for neurons (data not shown).

The primary element in cAMP signal transduction is the cAMP-dependent activation of PKA, which mediates many cAMP actions through phosphorylation of serine threonine residues in target proteins (20). Our results demonstrate that the effect of forskolin was abolished when PKA activity was inhibited, indicating that kinase A activity was important for the forskolin effect. The data seem to be true since the major effect of cAMP during development of many tissues is through activation of kinase A anchor protein. This protein, that can be directly activated by PKA, leads to an increase in the survival and/or differentiation of cell populations, playing an important role in the amplification of the cAMP signaling pathway (21).

Literature data have demonstrated the role of PKC activation in the survival of retinal ganglion cells (22), as well as the crosstalk between the cAMP and PI-3 signaling pathway in pancreatic cells (23). Interestingly, the inhibition of PKC activity completely abolished the effect of forskolin on ganglion cell survival in mixed retinal cultures. These results suggest the possible crosstalk between PKA and PKC pathways in our preparation.

In order to test a possible involvement of tyrosine kinase enzymes in the effect of forskolin we used inhibitors of these enzymes, $10 \mu \mathrm{M}$ genistein and $1 \mathrm{ng} / \mathrm{ml}$ herbimycin. Our results demonstrate that when the tyrosine kinase pathway was blocked the effect of forskolin was abolished. One possible explanation for this result involves the participation of trophic factors in this effect. One class of trophic molecules, the neuro- 
trophins, binds to several Trk receptors and stimulates several intracellular proteins such as MAPK and PI-3 kinase leading to cell survival (24). Our results also show that inhibitors of these enzymes blocked the effect of forskolin on retinal ganglion cell survival, showing that these enzymes are essential for the forskolin effect, allowing us to assume that forskolin may increase the release of trophic molecules in mixed culture medium. This hypothesis is corroborated by our finding that the inhibitor of polypeptide release brefeldin A blocked the effect of forskolin. Based on these results, we can suggest that an increase in cAMP levels could mediate an enhancement in the release of trophic molecules.

It has been demonstrated that glial cells produce and release trophic molecules after appropriate stimulation $(16,18,25)$. Accordingly, glial cells could be a possible source of trophic molecules. Since in our preparation these cells retain their proliferative capacity during culture in vitro we decided to study the effect of forskolin in the presence of an inhibitor of cell division. Our results clearly demonstrate that fluorodeoxyuridine entirely abolished the effect of forskolin, suggesting that Müller cells could be responsible for the major release of trophic molecules in mixed retinal cell cultures.

Literature data have provided evidence that cholinergic neuronal activity is essentially involved in the regulation of BDNF and NGF mRNAs in the developing and adult rat hippocampus (26). Since there is a cholinergic subpopulation of amacrine cells in the retina (27), we decided to investigate the possible role of acetylcholine in the effect elicited by forskolin. Our results show that the muscarinic receptor antagonist atropine completely blocked the forskolin effect on ganglion cell survival. Based on this result, we decided to test specific muscarinic antagonists, telenzepine and DAMP, in order to verify which subtype of muscarinic receptors was involved. We observed that telenzepine was capable of inhibiting the forskolin effect, showing that the activation of M1 receptors plays an important role in the increase in ganglion cell survival elicited by forskolin. These data are in agreement with the results obtained with BAPTA-AM since M1 stimulation elicits an increase in intracellular calcium levels induced by PI-3 receptor stimulation (28).

In a previous study, Pereira and Araujo (29) demonstrated that $3 \mu \mathrm{M}$ veratridine increased the survival of retinal ganglion cells, an effect also mediated by acetylcholine. These investigators showed that the veratridine effect was not mediated by L-type calcium channels but was mediated by T-type calcium channels. This result leads us to speculate about a role for T-type calcium channels in the release of acetylcholine from a subpopulation of amacrine cells in our cultures.

Meyer-Frank et al. (30) demonstrated that purified cultures of retinal ganglion cells, in contrast to other types of neurons studied, exhibited almost no responsiveness to trophic factors unless their intracellular cAMP levels were simultaneously elevated. Following axotomy, retinal ganglion cells may fail to survive not only because they do not obtain survival signals but also because they have impaired responsiveness to these signals (31). Intact rat retinas treated with $10 \mu \mathrm{M}$ forskolin show subsets of amacrine cells and displaced amacrine cells that markedly increase the immunoreactivity for cAMP (31). Other important data are spontaneous activity waves which sweep across the developing mammalian retina and influence the pattern of ganglion cell connections. These waves are driven by synaptic input from cholinergic amacrine cells where high levels of cAMP and PKA regulate the precise spatial and temporal patterns of spontaneous neural activity (32). Since during development ganglion and amacrine cells differentiate early (33) it is reasonable to assume the occurrence of an effective interaction between 
them. These very interesting results are in agreement with our data since they indicate that cholinergic activity plays an important role during development by controlling ganglion cell survival or differentiation.

The data presented here allow us to suggest a model for the effect of forskolin on ganglion cell survival in mixed retinal cell cultures. High levels of cAMP following forskolin treatment possibly stimulate cholinergic amacrine cells to release acetylcholine (34). This neurotransmitter, by stimulating M1 receptors, could induce an increase in the release or production of trophic molecules from neuronal and glial cells $(25,27$, 32). Since it was observed that M1 receptors present in astrocytes modulate the release of trophic molecules (35), and Müller cells (the major glial population in the retina) belong to the astrocytic lineage, we may propose the presence of these receptors in this population (36). Trophic molecules released by Müller cells may be responsible for the increase in the survival of ganglion cells through activation of PI-3 kinase and MAPK pathways, as was extensively demonstrated (37). On the other hand, high levels of cAMP could up-regulate the expression of neurotrophins and neurotrophin receptors on the plasma membrane of retinal ganglion cells in astroglial cultures and in the rat frontal cortex and hippocampus (38-40), allowing ganglion cells to better respond to trophic molecules released by glial cells in our cultures.

Further studies will be performed in order to identify which cells express M1 receptors in our cultures and which trophic molecules are involved in the increase in retinal ganglion cell survival.

\section{Acknowledgments}

We would like to thank Alexandre José Fernandes, Bernardino Matheus dos Santos and Jonas Borges da Silva for technical assistance. We also thank Dr. Roberto Paes de Carvalho for helpful suggestions and critical comments about the data.

\section{References}

1. Vaux DL \& Korsmeyer SJ (1999). Cell death in development. Cell, 96: 245-254.

2. Stewart BW (1994). Mechanisms of apoptosis: integration of genetic, biochemical and cellular indicators. J ournal of the National Cancer Institute, 86: 1287-1296.

3. Oppenheim RW (1991). Cell death during development of the nervous system. Annual Review of Neuroscience, 14: 453501.

4. Hamburger V \& Levi-Montalcini R (1949). Proliferation, differentiation and degeneration in the spinal ganglia of the chick embryo under normal and experimental conditions. J ournal of Experimental Zoology, 111: 457-501.

5. Snider WD (1994). Functions of the neurotrophins during nervous system development: what the knockouts are teaching us. Cell, 77: 627-638.

6. Thoenen H (1995). Neurotrophins and neuronal plasticity. Science, 270: 593-598.

7. Götz R, Köster R, Winkler C, Raulf F,
Lottspelch F, Schartl M \& Thoenen $\mathrm{H}$ (1994). Neurotrophin-6 is a new member of the nerve growth factor family. Nature, 372: 266-269.

8. Hallböök F, Ibáñez CF \& Persson H (1991). Evolutionary studies of the nerve growth factor family reveal a novel member abundantly expressed in Xenopus ovary. Neuron, 6: 845-858.

9. Maisonpierre $P C$, Belluscio $L$, Squinto $S$, Ip NY, Furth ME, Lindsay RM \& Yancopoulos GD (1990). Neurotrophin-3: a neurotrophic factor related to NGF and BDNF. Science, 247: 1446-1451.

10. Carter BD \& Lewin GR (1997). Neurotrophins live or let die: Does p75 NTR decide? Neuron, 18: 187-190.

11. Barbacid M (1994). The Trk family of neurotrophin receptors. J ournal of Neurobiology, 25: 1386-1403.

12. Barde YA (1989). Trophic factors and neuronal survival. Neuron, 2: 1525-1534.

13. Franklin JL \& J ohnson EM (1992). Sup- pression of programmed neuronal death by sustained elevation of cytoplasmic calcium. Trends in Neurosciences, 15: 501508.

14. Spiegel $A M$, Shenker $A$ \& Weinstein LS (1992). Receptor-effector coupling by Gproteins: implications for normal and abnormal signal transduction. Endocrine Reviews, 13: 536-565.

15. Beavo JA \& Reifsnyder DH (1990). Primary sequence of cyclic nucleotide phosphodiesterase isoenzymes and design of selective inhibitors. Trends in Physiological Sciences, 11: 150-155.

16. Hanson J $r$ MG, Shen $S$, Wiemelt AP, MCMorris FA \& Barres BA (1998). Cyclic AMP elevation is sufficient to promote the survival of spinal motor neurons in vitro. J ournal of Neuroscience, 18: 73617371.

17. Michel PP \& Agid Y (1996). Chronic activation of the cyclic AMP signaling pathway promotes development and long- 
term survival of mesencephalic dopaminergic neurons. J oumal of Neurochemistry, 67: 1633-1642.

18. Edwards SN, Buckmaster AE \& Tolkovsky AM (1991). The death program in cultured sympathetic neurones can be suppressed at a posttranslational level by nerve growth factor, cyclic AMP and depolarization. J ournal of Neurochemistry, 57: 21402143.

19. Mesulam M (1978). Tetramethylbenzidine for horseradish peroxidase neurohistochemistry. A non-carcinogenic blue reaction product with superior sensitivity for visualizing neural afferents and efferents. J ournal of Histochemistry and Cytochemistry, 26: 106-117.

20. Beebe SJ (1994). The cAMP-dependent protein kinases and CAMP signal transduction. Seminars in Cancer Biology, 5: 285-294.

21. Feliciello A, Gottesman ME \& Avvedimento $V$ (2001). The biological functions of A-kinase anchor proteins. J oumal of Molecular Biology, 308: 99-114.

22. Santos AA \& Araujo EG (2000). The effect of PKC activation on the survival of rat retinal ganglion cells in culture. Brain Research, 853: 338-343.

23. Liu YJ , Grapengiesser E, Gylfe E \& Hellman B (1987). Crosstalk between the CAMP and inositol triphosphate-signaling pathways in pancreatic cells. Archives of Biochemistry and Biophysics, 334: 295302.

24. Kaplan DR \& Miller F (2000). Neurotrophin signal transduction in the nervous system. Current Opinion in Neurobiology, 10: 381-391.

25. Schmalenbach C \& Müller HV (1993). Astroglial-neuron interactions that promote long-term neuronal survival. J ournal of Chemical Neuroanatomy, 6: 229-237.
26. Berzaghi MP, Cooper J, Castrén E, Zafra $F$, Sofroniew M, Thoenen H \& Lindholm D (1993). Cholinergic regulation of brainderived neurotrophic factor (BDNF) and nerve growth factor (NGF) but not neurotrophin-3 (NT-3) mRNA levels in the developing rat hippocampus. J ournal of Neuroscience, 13: 3818-3826.

27. Santos PF, Carvalho AL, Carvalho AP \& Duarte CB (1998). Differential acetylcholine and GABA release from cultured chick retina cells. European J ournal of Neuroscience, 10: 2723-2730.

28. Wotta DR, Wattenberg EV, Langason RB \& El-Fakahany EE (1998). M1, M3 and M5 muscarinic receptors stimulate mitogenactivated protein kinase. J oumal of Pharmacology, 56: 175-186.

29. Pereira SPF \& Araujo EG (1997). Veratridine increases the survival of retinal ganglion cells in vitro. Brazilian J ournal of Medical and Biological Research, 30: 1467-1470.

30. Meyer-Frank A, Kaplan MR, Pfrieger FW \& Barres BA (1995). Characterization of the signaling interactions that promote the survival and growth of developing retinal ganglion cells in culture. Neuron, 15: 805-819.

31. Shen S, Wiemelt AP, MCMorris FA \& Barres B (1999). Retinal ganglion cells lose trophic responsiveness after axotomy. Neuron, 23: 285-295.

32. Stellwagen $D$, Shatz $C J \&$ Feller $M B$ (1999). Dynamics of retinal waves are controlled by cyclic AMP. Neuron, 24: 673685.

33. Reese BE \& Collelo RJ (1992). Neurogenesis in the retinal ganglion cell layer of the rat. Neuroscience, 46: 419-429.

34. Yao W-D, Rusch J, Poo M-M \& Wu C-F (2000). Spontaneous acetylcholine secretion from developing growth cones of
Drosophila central neurons in culture: effects of CAMP-pathway mutations. J ournal of Neuroscience, 20: 2626-2637.

35. Knipper M, da Penha Berzaghi M, Blöchl $A$, Breer $\mathrm{H}$, Thoenen $\mathrm{H} \&$ \& Lindholm $\mathrm{D}$ (1994). Positive feedback between acetylcholine and the neurotrophins nerve growth factor and brain-derived neurotrophic factor in the rat hippocampus. European J ournal of Neuroscience, 6: 668-671.

36. Murphy S, Pearce B \& Morrow C (1986). Astrocytes have both $\mathrm{M} 1$ and M2 muscarinic receptor subtypes. Brain Research, 364: 177-180.

37. Dolcet $X$, Egea J , Soler RM, Martin-Zanca D \& Comella J X (1999). Activation of phosphatidylinositol 3-kinase, but not extracellular-regulated kinases, is necessary to mediate brain-derived neurotrophic factorinduced motoneuron survival. J ournal of Neurochemistry, 73: 521-531.

38. Meyer-Frank A, Wilkinson GA, Kruttgen A, Hu M, Munro E, Hanson J $r$ MG, Reichardt LF \& Barres BA (1998). Depolarization and CAMP elevation rapidly recruit Trk $B$ to the plasma membrane of CNS neurons. Neuron, 21: 681-693.

39. Condorelli DF, Dell'Albani P, Mudo G, Timmusk T \& Belluardo N (1994). Expression of neurotrophins and their receptors in primary astroglial cultures: induction by cyclic AMP-elevating agents. J ournal of Neurochemistry, 63: 509-516.

40. Morinobu S, Fujimaki K, Okuyama N, Takahashi M \& Duman RS (1999). Stimulation of adenylyl cyclase and induction of brain-derived neurotrophic factor and TrkB mRNA by NKH477, a novel and potent forskolin derivative. J ournal of Neurochemistry, 72: 2198-2205. 